\title{
Cement production output and prices trends in Mozambique
}

\author{
Daniel Baloi
}

\begin{abstract}
Cement plays a key role in construction of infrastructures around the world. Indeed, it is regarded as one of the most important materials. Its role in the construction industry in Mozambican is even much more significant than in other countries due to the entrenched construction conception, practices and customs. As such, the share of cement cost in the total construction cost has been very significant. Whenever cement prices fluctuate, there have been tremendous impacts on construction costs and, consequently, on its demand. The resulting shock waves propagate through the economy in general as well as housing and labour markets, in particular. There has been a perception that relatively high cement prices are due to the local low production capacity. Recent years have witnessed huge increase in cement production capacity as a result of good economic growth and good economic prospects.

This research analyses cement prices and production capacity trends over the last ten years in Mozambique in an attempt to determine any sort of association among the two variables. Preliminary results suggest that cement prices have had some relationship with production capacity in the current context. Without the significant production capacity increase over the last years, prices would have soared tremendously, given the strong association of production costs with currency value. However, the strength of relationship between production capacity and prices has not been determined due to the fact that there are many other factors at play, which require a detailed assessment.
\end{abstract}

Index Terms - capacity, cement, construction, demand, output, prices

\section{INTRODUCTION}

Mozambique faces a tremendous backlog of all kind of infrastructures. Significant efforts have been made over the years to curb the problem but there is still a long way to go in the next decades to minimize the strain. The need for infrastructures will continue to rise to respond to society increasing needs, as well as economic growth. Population growth, at a rate of $3 \%$ per year [1], is a significant contributor driving infrastructures demand, with particular emphasis on dwellings.

All structures ranging from buildings to civil engineering ones require availability and quality construction materials to become reality. The issue of availability, in particular, poses serious problems in many developing countries which lack manufacturing capacity. If certain construction materials cannot be produced locally, imports are then unavoidable, with all the financial and logistics implications. Yet it is true

Daniel Baloi, Department of Civil Engineering, Eduardo Mondlane University, Faculty of Engineering, Maputo, Mozambique that the production of specific goods depends on several economic variables, measures should be taken to minimize imports, which tend bring more burden than benefits in most cases. Local production promotes employment creation, reduces convertible currency demand, help to improve trade balance, just to mention few examples. This is significantly important for developing countries.

Cement has been as a prominent binder in concrete, blocks, stucco and mortar, among other uses. Cement is indeed present in structural elements of buildings, bridges, roads, dams, railways, irrigation and drainage systems, as well as in the buildings envelopes. It is probably the top construction material in most structures. For a large period of time until the first half of the nineties, the then existing production capacity catered well for the demand [2]. However, the economic expansion that followed led to construction industry revitalization and strong growth. The urbanization rate (approximately at 33\%), in particular, has been a major factor in demand increase. As the pace of construction production accelerated, it appeared that supply of cement started to lag far behind demand. This trend in cement consumption is not surprising at all. Indeed, global consumption has been on the increase in the last decades. In Africa for instance, consumption grew from 58 metric tons in 2000 to $179 \mathrm{mt}$ in 2010 and forecasts indicate figures around $250 \mathrm{mt} 2018$ as mentioned by [3]. The gap over the years was filled with recourse to imports. It is based on this evidence that a couple of investments have since taken place in the country in order to grab the prevailing opportunities [4]

\section{PORTLAND CEMENT}

Portland cements are hydraulic cements. These cements set and harden by reacting chemically with water through the hydration process. The other group is the pozzolanic cements, which are siliceous materials that develop hydraulic cementitious properties when lime is added. Ordinary Portland Cement OPC, generally known as Type I cement, consists of at least two-thirds by mass of calcium silicates, that is $3 \mathrm{CaO} \cdot \mathrm{SiO}_{2}$ and $2 \mathrm{CaO} \cdot \mathrm{SiO}_{2}$, from where elements such as calcium oxide, silicon oxide, aluminum oxide, ferric oxide are found and other compounds aimed at refining the quality and properties. It can be said that OPC is obtained by heating limestone with small quantities of other materials, usually clay, to approximately $1450{ }^{\circ} \mathrm{C}$. The resulting product from the heating is called clinker, which is subsequently ground with small quantities of gypsum to obtain OPC. Clinker proportion usually forms approximately $90 \%$ of the total ingredients. Clinkers are nodules with diameters ranging from 5 to $25 \mathrm{~mm}$ of a sintered material. The cement produced in Mozambique is Type I, general Portland cement. 


\section{HISTORICAL PERSPECTIVE}

The first cement plant in Mozambique was built in 1923 in Matola, some $10 \mathrm{~km}$ southwest of Maputo. Later on, 1953 and 1961, two additional plants were established in Beira and Nampula provinces. Until 2011 there were three cement production plants in Mozambique, namely Matola, Beira and Nacala respectively, all belonging to Cimentos de Moçambique. The locations of the plants are consonant with the planning logic at the time, namely to supply cement for development projects in the south, centre and north regions, respectively. Matola plant has been the largest plant for many years and contributes approximately $50 \%$ of the total production in the country [2].

The production of cement has, to some extent, depended on the imports of part of raw materials, namely clinker, despite the existence of abundant limestone reserves in the country. Matola plant has imported approximately $50 \%$ of its clinker and the remainder is produced locally, on the basis of limestone extracted in Salamanga, 60 kilometres to the South, from where it is transported to the plant through a dedicated railway. For approximately fifteen years, from 1982, both the railway and quarry were idle due to civil war. The railway capacity has been indicated as one of the factors hindering the increase of Matola plant cement output. An upgrade was likely a solution to the problem. It is important to mention that Mozambique has several scattered sources of limestone and clay whose exploitation could lead to an increase in terms of production capacity, as well as reduction in imports of some raw materials.

\section{Methodology}

Based on the stated problem and objective of the study, a methodology deemed appropriate has been devised. The study seeks to uncover the reasons why cement prices remain relatively high despite the steady increasing capacity over the last decade. From the perspective of a dynamic analysis of cement production and prices trends a ten years period has been chosen. This period of time has been selected because it was in it that the most significant, and probably dramatic, changes in terms of cement market and production capacity in particular took place. Relevant data pertaining to production capacity, demand, supply, clinker and cement imports, cement prices, economic and financial indicators, were collected from industry analysis reports, companies' records, National Statistics Authority and Government reports. Data analysis was performed by means of descriptive statistics.

\section{CEMENT PRODUCTION}

A key reference of cement production volume is given in fig. 1 [2]. The data is provided as an historical perspective of the industry and not as part of the envisaged analysis. As depicted, cement production levels between 1986 and 1997 were marginal compared to current figures. It is worth highlighting that in most of that period, up to end of 1992, the country experienced tremendous economic and social difficulties due to civil war. The economic activity, construction in particular, was at its lowest level. Economy recovery signs started from 1994 after the first general elections were held. Foreign investments started to flow into the country fostering new businesses and an increase in infrastructures and housing demand.

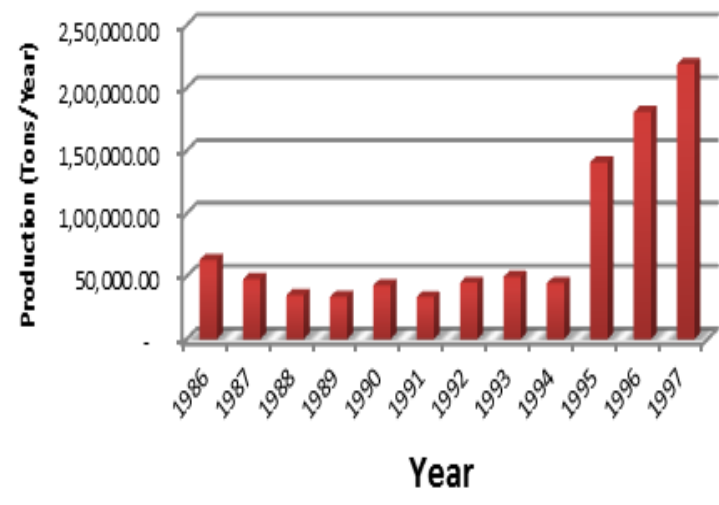

Figure 1: Cement production from 1986 up to privatization in 1997

Although production capacity was in place effective production was very low, approximately below 50.000 tons per year from 1986 to 1994 . It is worth mentioning that production capacity of the only cement company across the country was increased to about 800.000 tons in the 70 s. As such, outputs below 50.000 tons represented huge and undesirable inefficiencies. The situation was reverted from 1995, as shown in the above picture.

\section{Number of plants}

The number of plants has been on the rise for the last decade as a reflection of significant investments in the sector. The number grew from just 3 to approximately 14 in 2018, that is, approximately five times [4]. There are more plants in the pipeline and being built based on data from the Investments Agency. The investments in cement production have ground on the prospects of economic growth of the country largely pushed by natural resources discoveries. It is expected that large resource-based projects require significant infrastructure in the coming years.

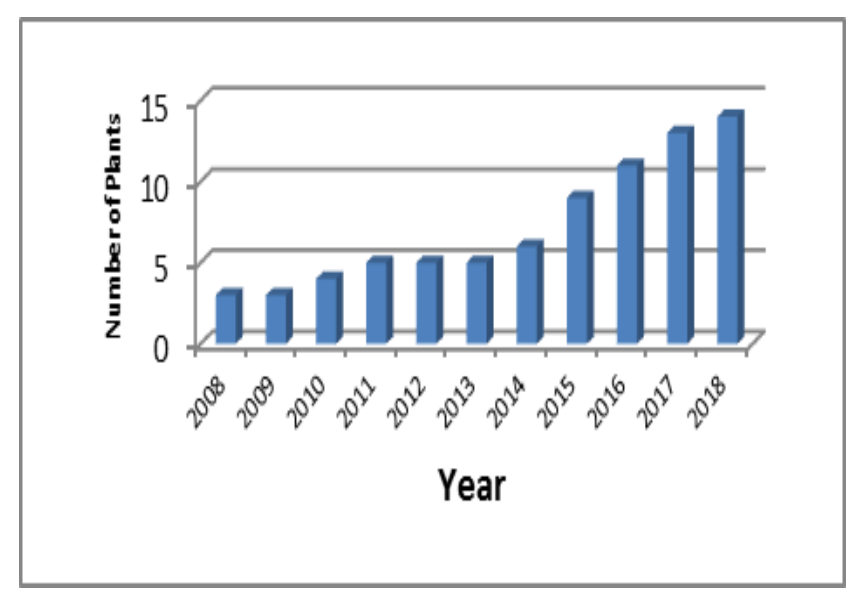

Figure 2: Number of cement plants

A common feature in most of the plants is that they are not integrated facilities and depend on clinker imports from which they produce cement. There is only one exception where an integrated plant is prepared to source local raw materials, manufacture clinker and then grind it to produce cement. 
International Journal of Engineering and Technical Research (IJETR) ISSN: 2321-0869 (O) 2454-4698 (P) Volume-8, Issue-6, June 2018

\section{Production capacity}

Following the increase in the number of plants across the country, there has been a significant capacity growth. As depicted in fig. 3, the production capacity in 2008 stood below one million tons per year compared to approximately five millions tons ten years later [4]. The largest increase occurred in the last four years starting in 2014. This trend in the country follows that of the African continent where massive investments have occurred in recent years. Many countries have overcome cement deficit and have surplus. It is interesting to note that despite such robust capacity, efficiency has been a concerning issue. According to recent estimates, current consumption stands at more or less two millions tons per year. As such, the efficiency has been in region of $50 \%$. The reasons behind the low level of capacity use are various, being the main the economic slow-down from 2015 to date. Consumption forecasts did not materialize due to reduction in demand. Indeed, many housing and infrastructure construction projects were slashed across the country. Both private and public spending shrunk significantly. For example, large transportation, mining, commercial and institutional projects were stopped or postponed since 2015. Furthermore, housing construction by families, a common practice, has reduced. It is expected that the situation will improve when the economy goes back to the trail but recovery will take time and various plants will be operating well below capacity.

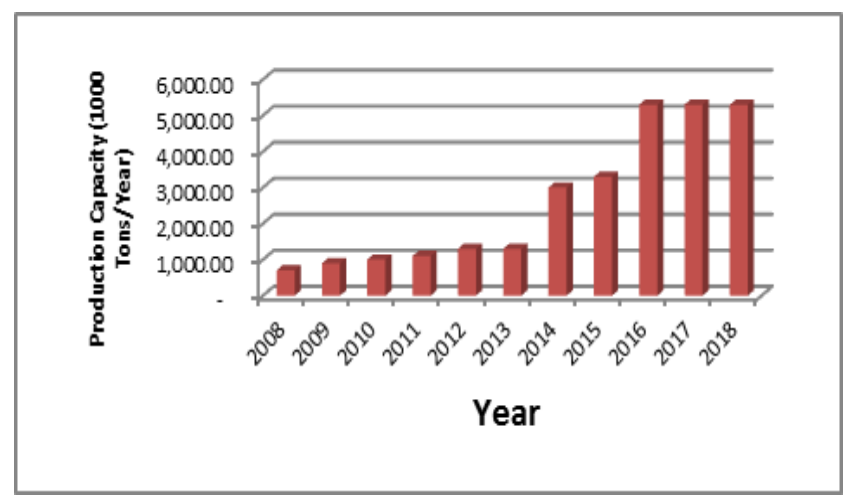

Figure 3: Cement production capacity

\section{Exchange rate and inflation}

The analysis of cement price trends involves a description of their variations as well as two of the main triggers for such behaviour, namely the exchange rates and inflation. Due to the small size and structural weaknesses of the local economy there is a large portion of the country trade denominated in foreign currencies. In such circumstances, the inflation is strongly influenced by exchange rates. The analysis is based upon a $50 \mathrm{~kg}$ sack, 32,5 N specification and Maputo market. There are differences in cement prices across regions but Maputo is used as a reference since it is the largest and most important market.

The importance of exchange rate derives from the fact that a large portion of raw materials for cement production in the country, namely clinker, is imported which clearly affects selling prices. The trend of average exchange rate between USD/ MZM, as well as the inflation rate over time are shown in fig. 4. While there is a noticeable slump of the exchange rate in 2010, there was an overall stability over the period of five years until 2012. In fact, only in 2015 a pronounced jump that continued through 2018 is noticed [5].

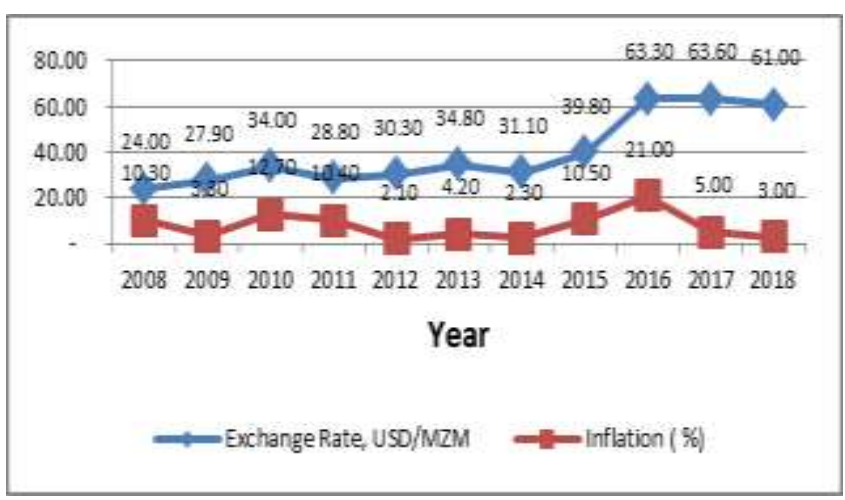

Figure 4: Exchange rate and inflation trends over time

The MZM loss of value between 2012 and 2018 more than doubled, as a direct impact of economic and financial crisis affecting the country.

With regard to inflation, it was within expected patterns over a long period of time starting in 2008 , but it experienced a dramatic surge in 2015 reaching 10,5\%, from $2,3 \%$ from previous year. The following year it picked up even further reaching $21 \%$. The figures are not surprising, as they followed the currency value loss in an economy largely dependent on commodities coupled with low production capacity. Nevertheless, the inflation has been under control since then due to fiscal and monetary measures taken.

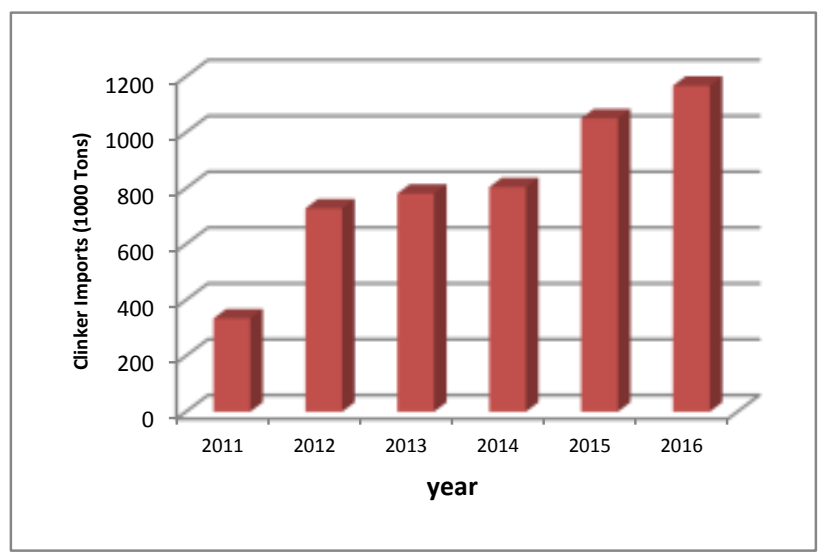

Figure 5: Clinker imports

The combination of exchange rates and inflation over the period of analysis has the potential to push cement prices up in a significant magnitude. The exchange rate in particular is expected to have large impact on prices since most plants depend on clinker imports. The volume of clinker imports witnessed a significant increase between 2011 and 2016 as depicted in fig. 5 [4]. It is important to stress the fact that there have been imports of cement from various markets, as well. These imports have been very competitive thus contributing to balance cement prices. Inflation has obviously an influence but its magnitude depends on the size of specific inputs prices movement. For example, labour costs have had minor influence on the total production costs.

\section{Prices trends}

An observation of cement prices lead to the conclusion that they were generally stable over a long period of time from 2008. There were minor justifiable price changes (these are current prices) as shown in fig. 6 . In fact, price of a $50 \mathrm{~kg}$ bag, $32.5 \mathrm{~N}$, of cement sold at MZM 220,0 in 2008 and increased 
to MZM 230 in 2009 and MZM 250,0 in 2011 - 2015 [4]. This corresponds to an increase of $14 \%$ over seven years, which is very reasonable and probably significantly below the currency devaluation and inflation rates effects throughout the period. Taking currency loss of value into account in the tune of $41 \%$ and cumulative inflation, a much higher increase in prices would be expected and not a mere $14 \%$ over a seven years period, as depicted in fig. 7. That was not the case, partially because the share of imports constitutes a fraction of total production costs and cement imports may have helped. Cement imports in recent years were estimated at $20 \%$ of total consumption. There are other cost components which are not influenced by the exchange rate. The volume of clinker imports between 2011 and 2016 which can help to envisage the weight of foreign currency on the total cost of cement production is depicted in figure 5. Clinker imports in 2011 amounted to approximately 250 million tons and experienced a significant increase to reach more 1100 million tons in 2016. Apart from the exchange rate, inflation is expected to influence costs variables, particularly those pertaining to local inputs. A careful examination of inflation trend over the same period shows that the cumulative inflation is higher than the price change magnitude between 2008 and 2015. Indeed, cumulative inflation between the above mentioned timeframe is approximately $70 \%$. Nevertheless, it should be stressed that the level of inflation varies across different inputs with some having very high and others very low values. Statistical single value inflations represent averages.

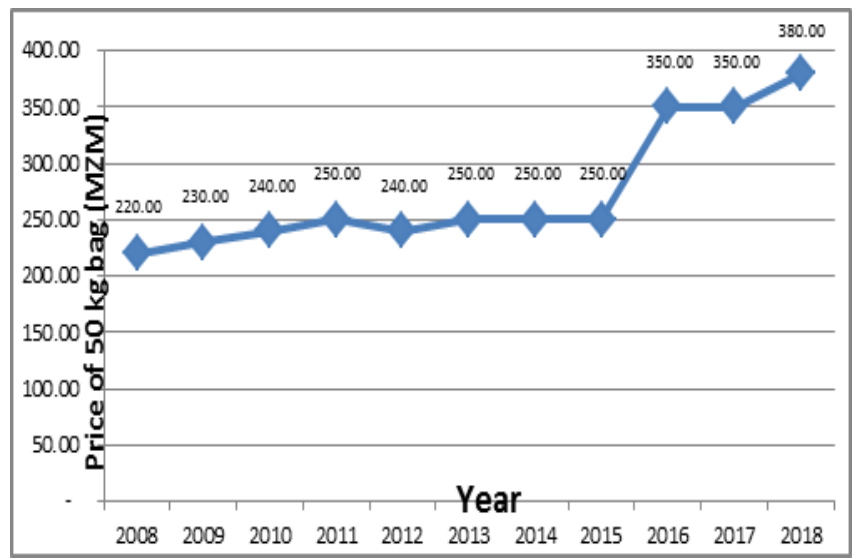

Figure 6: Cement prices trend $(50 \mathrm{~kg}$ bag)

\section{Problems in 2015/2016}

Of particular interest in terms of prices is the critical period spanning 2015 and 2016 where prices hike were massive. Overall, average cement prices rose from MZM 250 to MZM 350 , corresponding to an increase of 59\% [4]. In this period, the currency lost approximately half of its value, with the exchange rate starting from 40 at the beginning of 2015 and reaching a staggering level of 80 at the end of 2016. Taking into account currency devaluation higher prices increases were expected. For example, one manufacturer mentioned that between September 2015 and September 2016 production costs rose by $50 \%$, mainly due to clinker imports, while prices rose only by $32 \%$. This has obviously implications on the profitability of the businesses, unless cost cutting measures are implemented. Anyway, these high prices increase led to a significant drop in demand. Cement consumption volumes shrunk largely from 2015 onwards and manufacturers had to reduce output even further.

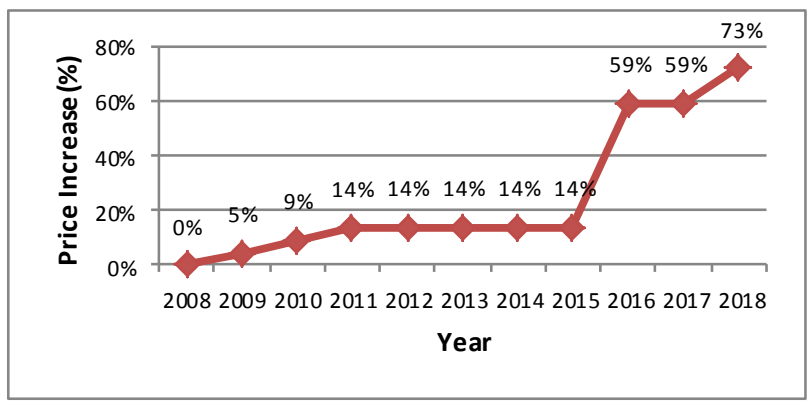

Figure 7: Rate of prices increase over years $(50 \mathrm{~kg} \mathrm{bag})$

Obviously, this is a very peculiar case originating from global financial and economic crisis with local impact. Otherwise, prices trends would have followed observed patterns before the crisis, that is, very smooth prices changes, on the rise, over time but at lower rates compared to currency depreciation and inflation.

\section{Influence of output on prices}

Having ascertained how cement prices changed over time in line with the main potential drivers, namely exchange rate and inflation, it is important to establish the extent to which the production capacity increase contributed to curb prices picks. In principle, based on economics laws, as output increased and translated into supply, prices would have been dropping. Did this happen in fact? It seems that, apparently, cement prices did not decrease. From the perspective of current nominal prices there was no benefit from increased capacity. From this angle, prices increased slightly. However, an analysis based on real prices would reveal a different picture. A close examination of prices trend between 2008 and 2015 reveals a cumulative increase in price of $14 \%$, yet the cumulative average inflation is in the region of $70 \%$ and currency depreciated $66 \%$ approximately. A detailed of production cost analysis would enable to identify the weight of clinker on the total cost and thus determine the real impact of imports. In addition, a close examination of inflation figures associated with the main inputs would help to determine its influence on costs. Another variable of interest in the equation is the contribution of cement imports into the market prices.

\section{Cement consumption per capita}

An analysis of cement consumption per capita over the period shows a marginal increase for some time up to 2014. Then, there was a single uncommon peak in 2015 and subsequent drop in the following years. From the fig. 8 it can be concluded that consumption in the country is still very low compared to other developing countries, particularly in the region where the numbers are close or above $100 \mathrm{~kg}$.

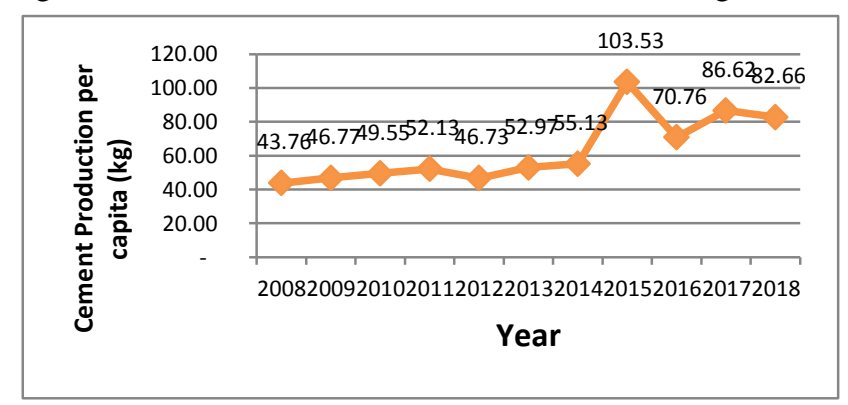

Figure 8: Cement consumption per capita 
Recent studies [3] on the continent indicate an average consumption per capita around $250 \mathrm{~kg}$, which is very significant. So it appears to be a paradox when consumption is at low levels yet the installed capacity cannot be properly utilized due to limited demand. The explanation lies in the economic weakness leading to low purchasing power.

\section{CONCLUSION}

The paper set out to briefly highlight contours of cement production capacity in Mozambique and its influence on selling prices. There is a general perception that cement prices are very high, particularly for the average consumers. This is perceived as an important factor behind high construction costs bearing in mind that cement is one of the most crucial inputs. Relevant data pertaining to production capacity show that there has been a significant increase over the last decade having been added 12 new plants from only 3 in 2008. The total production capacity now stands at approximately 6 million tons per year against 1.3 million tons a decade ago. As a result of the increased capacity import taxes have been aggravated in attempt to protect the industry.

Based on currency value erosion and cumulative inflation it appears cement prices would have risen much more than they did. The supply side can thus be considered a cushion that helped to absorb the impact. Current selling prices are justifiable by a combination of factors of which stronger capacity is part. However, considering the production capacity growth, there were bigger expectations of lower prices. At this point it is not possible to determine the extent to which production capacity increase influence prices. Additional research is thus required to determine the influence and magnitude of other contributing factors to cement prices. These factors include demand decrease due to limited purchasing power, continued cement imports including an informal market, emergence of integrated plants that source raw materials locally thus avoiding imports. In particular, a thorough detailed production cost analysis would shed light into the weight of each input on the total production costs.

\section{BIBLIOGRAPHY}

[1] Instituto Nacional de Estatística de Moçambique: Anuário Estatístico (Statistical Yearbook 2012 - 2016) www.ine.gov.mz

[2] Sutton, John 2014, MAPA EMPRESARIAL DE MOÇAMBIQUE, InternationalGrowthCentre, London

[3] De Moo, Yves, A trader's view Overcapacity: How long will Africa remain a solution as an offset destination? Global Cement MAGAZINE, January 2013

[4] Ministry of Industry and Trade, Mozambique (2018), www.mic.gov.mz [5] Anuário Estatístico de Moçambique (2014 - 2017) . www.ine.gov.mz

[6] Ad Ligthart, Current developments in the cement industry and the consequences for cement and clinker shipping. www.cementdistribution.com

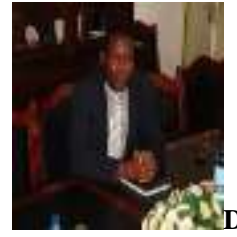
Civil Engineering, Eduardo Mondlane University. He has been actively involved in construction engineering consultancy. His research interests span risk management, construction management, project management, productivity as well as construction industry development. He is a member of the Institution of Engineers, American Society of Civil Engineers and Project Management Institute. 